\title{
Pemberdayaan Potensi Desa Wisata River Walk di Desa Papasan Kecamatan Bangsri Kabupaten Jepara
}

\author{
Zahrotun Nafisah, Miswan Ansori \\ Fakultas Syariah dan Hukum, UNISNU Jepara \\ zahro@unisnu.ac.id
}

\begin{abstract}
Abstrak
Kegiatan pengabdian kepada masyarakat (PKM) ini bertujuan untuk pemberdayaan desa Papasan yang berpotensi menjadi desa wisata dengan kearifan lokal serta memiliki kekayaan alam yang cukup potensial. Namun, sayangnya Pemda Kabupaten Jepara masih minim untuk mengekspos kekayaan lokal yang dimiliki tiap desa di Jepara yang seharusnya dapat menjadi devisa tersendiri bagi pengelolaan daerah. Kegiatan ini dilaksanakan bersama mitra pemerintah desa setempat untuk mengidentifikasi dan mengembangkan potensi desa bersama para pemuda yang tergabung di Karang Taruna dengan bantuan sebagian masyarakat desa. Metode ABCD (Asset Based Community Development) yang digunakan untuk mengupayakan inovasi wisata atas aset/potensi desa yang ada untuk meningkatkan taraf hidup masyarakat. Melalui tahap kegiatan berikut; mengidentifikasi potensi desa, membuat icon wisata Pesona Papasan River Walk yang disertai dengan penyemaian bibit ikan untuk area pemancingan, dan mensosialisasikan desa wisata di media massa dan media lainnya. Dengan beberapa kegiatan tersebut, desa Papasan akan menjadi salah satu destinasi desa wisata baru yang akan dikunjungi para wisatawan dan dapat meningkatkan taraf hidup masyarakat setempat.

Kata Kunci: Pemberdayaan, River Walk, Papasan Bangsri, Kabupaten Jepara.
\end{abstract}

\begin{abstract}
This activity of community service based on PKM is aimed at empowering Papasan village which has the potential to become a tourism village with local wisdom and has sufficient natural resources. However, unfortunately the Jepara Regency Government is still minimal to expose the local wealth owned by each village in Jepara which should be able to become its own foreign exchange for regional management. This activity was carried out with local village government partners to identify and develop village potential with young people who are members of Karang Taruna with help of some village communities others. The Asset Based Community Development (ABCD) method is used to strive for tourism innovation of existing village assets/potential to improve people's live. Through the following activity stages; identifying village potential, creating a Pesona Papasan River Walk tourism icon accompanied by sowing fish seeds for fishing areas, and promoting tourism village in the mass media and other media. With some these activities, Papasan village will become one of the new tourist village destination that will be visited by tourist and can improve the standard of living of the local community.
\end{abstract}

Keywords: Empowerment, River Walk, Papasan Bangsri, Jepara Regency. 


\section{PENDAHULUAN}

Rencana Strategis Nasional Kementrian Kebudayaan dan Periwisata sejak tahun 2010, telah banyak mendengungkan program peningkatan dan pengembangan pariwisata diantaranya potensi Desa Wisata. Karena, kini wisatawan lebih tertarik pada wisata alam yang menyuguhkan area pedesaan. Di Kabupaten Jepara sendiri memiliki banyak desa yang kaya dengan kearifan lokal berupa kekayaan alam, hasil bumi, letak geografis yang terdiri dari sungai, laut dan pegunungan.

Salah Satunya adalah Desa Papasan di Kecamatan Bangsri Kabupaten Jepara Jawa Tengah. Dengan batasan geografis di sebelah utara berbatasan dengan Desa Dudakawu, sebelah timur berbatasan dengan perhutani/lereng Gunung Muria. Batas sebelah Selatan adalah Desa Tanjung, dan sebelah barat berbatasan dengan Desa Srikandang.

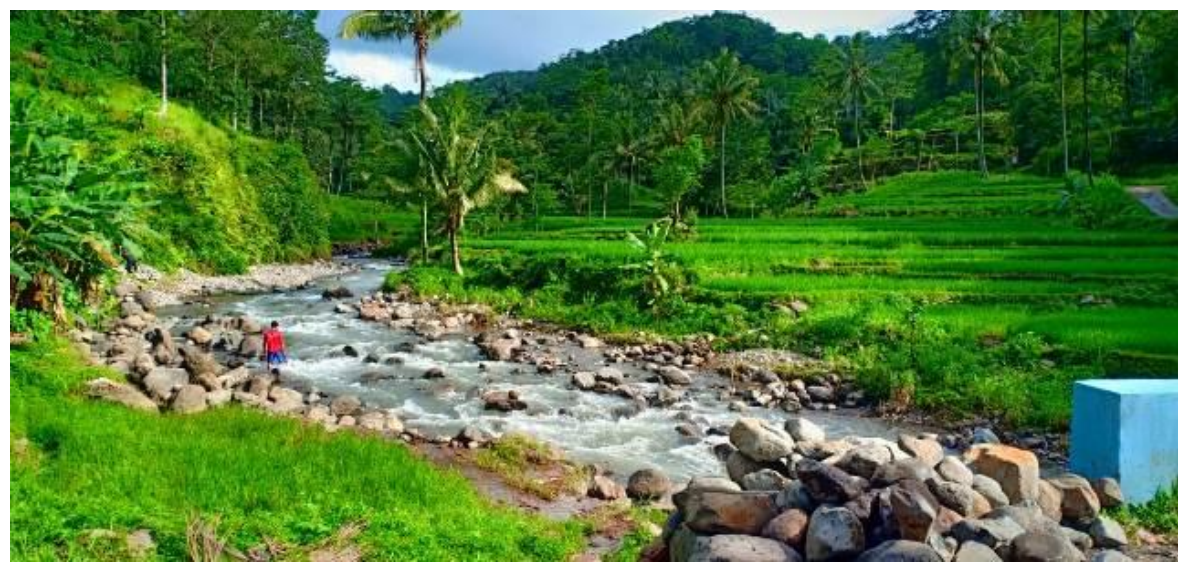

Gambar 1. Potensi alam desa Papasan Kecamatan Bangsri Jepara

Desa Papasan memiliki luas wilayah 862.510 ha atau $8,63 \mathrm{~km}^{2}$, berada 500 700 meter di atas permukaan laut yang bertopografi lereng/punggung bukit. Secara administrasi Desa Papasan memiliki penduduk 1.863 jiwa dengan kepadatan penduduk 25orang/Ha terbagi menjadi 3 Rukun Warga (RW) dan 13 Rukun Tetangga (RT). Ada 9 dukuh di Desa Papasan serta terdapat LKMD dengan kriteria berkembang.

Masyarakat desa Papasan mayoritas berprofesi sebagai petani dan buruh, dan memiliki gaya hidup yang sosialis serta agamis. Tidak banyak ditemui masyarakat yang antusias untuk mengembangkan desanya menjadi Desa Wisata. Karena menganggap bahwa tidak lebih menguntungkan dengan pekerjaan sebagai petani dan buruh.

Namun dalam kegiatan Pengabdian Kepada Masyarakat ini tim pengabdian telah merangkul masyarakat setempat untuk ikut mengembangkan dan 
menyosialisasikan Desa Wisata River Walk dengan menggandeng para pemangku jabatan yang ada di Desa Papasan serta tokoh masyarakat yang ada.

\section{METODE}

Kegiatan pengabdian kepada masyarakat ini dilaksanakan pada bulan Maret sampai Juli 2019 dengan menggunakan metode ABCD (Asset Based Community Development). Yakni mengupayakan inovasi wisata yang ada di desa Papasan Kecamatan Bangsri Kabupaten Jepara dengan mengimplementasikan pembuatan icon Pesona Papasan River Walk di salah satu area sungai yang menjadi destinasi alternatif bagi wisatawan yang hendak menuju Air Terjun Gembong dan Air Terjun Kedung Ombo.

Dengan metode ABCD dapat mengutamakan pemanfaatan asset/potensi desa berupa kekayaan alam dengan memberikan tambahan berupa karya inovatif pemberdayaan masyarakat setempat. Pendekatan social yang digunakan juga merupakan pendekatan multiaksi yang merangkul masyarakat desa untuk lebih sadar lingkungan dan turut mengembangkan desa wisata. Adapun tahapan pelaksanaan dalam kegiatan ini yaitu:

\section{A. Perencanaan}

Dalam tahap perencanaan, tim pengabdian mengidentifikasi permasalahan mitra, dan mengkomunikasikan segala hal mengenai pelaksanaan pengabdian baik berupa keadministrasian maupun konsep pelaksanaan.

\section{B. Pelaksanaan}

Pada tahap pelaksanaan, tim pengabdian bersama dengan mitra membuat icon Pesona Papasan River Walk di sekitar sungai akses menuju Air Terjun Gembong dan Air Terjun Kedung Ombo yang dapat dijadikan sebagai titik awal menuju kedua destinasi wisata tersebut atau bahkan dijadikan sebagai destinasi alternative bagi wisatawan.

\section{Sosialisasi dan Evaluasi}

Pada tahap sosialisasi, tim pengabdian menyosialisasikan kegiatan kemitraan pada pengembangan potensi desa wisata melalui media massa. Di tahap akhir yaitu evaluasi kegiatan yang dilakukan setiap akhir kegiatan di laksanakan untuk dapat mengukur keberhasilan program pengabdian kepada masyarakat ini. 


\section{HASIL DAN PEMBAHASAN}

Berdasarkan metode yang telah dirancang, kegiatan program kemitraan masyarakat ini telah melaksanakan:

\section{A. Tahap perencanaan}

Adapun awal perencanaan kegiatan ini, tim pengabdian telah berkomunikasi dengan Kepala Desa setempat untuk membicarakan kesediaan sebagai mitra dalam program ini dan mengidentifikasi berbagai permasalahan yang dihadapi mitra dalam pengembangan desa.

Melalui wawancara dan diskusi terbatas dengan bapak Ahmad Sukron menghasilkan perencanaan kegiatan dan konsep pelaksanaan seperti: jadwal pelaksanaan kegiatan, peserta kegiatan dan pembuatan daftar hadir, serta peninjauan lokasi yang akan dijadikan sebagai icon titik destinasi desa Papasan.

Selanjutnya atas instuksi kepala Desa Papasan tim pengabdian bersama ketua pemuda Karang Taruna, berkolaborasi untuk membuat desain icon Pesona Papasan River walk yang akan dipasang di titik lokasi. Dengan membuat beberapa ketentuan tulisan yang disesuaikan dengan tujuan kegiatan ini.

\section{B. Tahap Pelaksanaan}

Di awal tahap pelaksanaan kegiatan pengabdian ini yakni pembuatan icon Pesona Papasan River Walk yang dibantu oleh pengrajin kayu di Desa Papasan. Pembuatan icon bertujuan untuk menjadikan daya tarik tersendiri bagi orangorang yang datang ke desa Papasan. Di samping itu, icon ini merupakan awal dari adanya pengembangan desa wisata yang akan dapat dipromosikan warga melalui berbagai media.
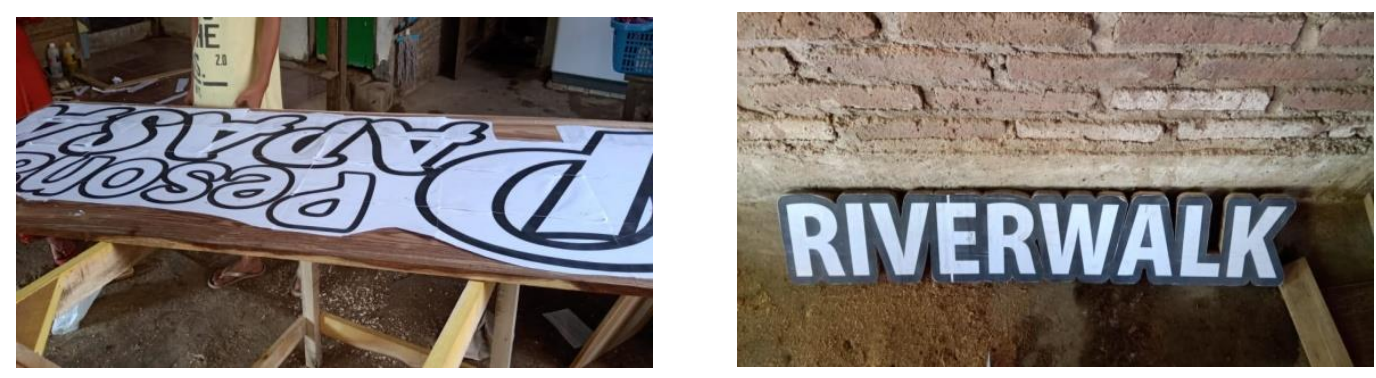

Gambar 2. Proses pembuatan icon oleh pemuda Karang Taruna

Pada tahap kedua adalah pemasangan icon Pesona Papasan River Walk yang diikuti oleh para pemuda Karang Taruna dan pejabat desa setempat serta beberapa warga desa. Kegiatan ini diawali dengan Jumat bersih di area sungai dan akses jalan menuju sungai. Warga sangat antusias bekerjasama dalam kegiatan ini dan gotong royong untuk memperindah kawasan ini. 


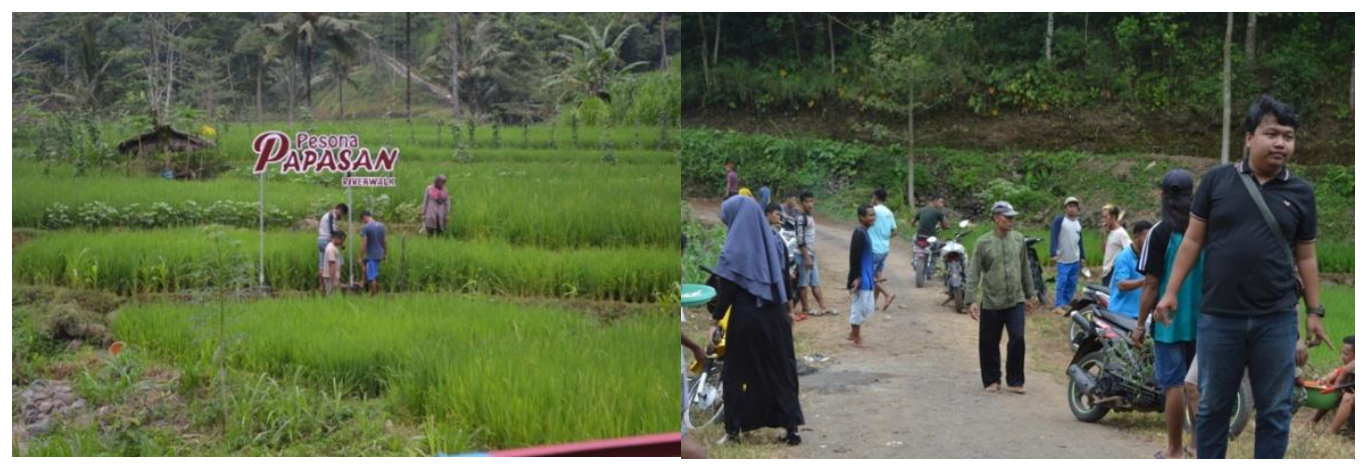

Gambar 3. Pemasangan icon Pesona Papasan dan kerja bakti masyarakat

Sebagian warga ada yang bertugas menyiapkan bibit ikan yang akan disemaikan di sungai untuk dijadikan area pemancingan alam. Area sungai telah sedikit dibatasi agar bibit ikan tersebut dapat berkembangbiak dan nantinya dapat menjadi daya tarik para pendatang untuk sekedar memancing dan berfoto di desa Papasan.

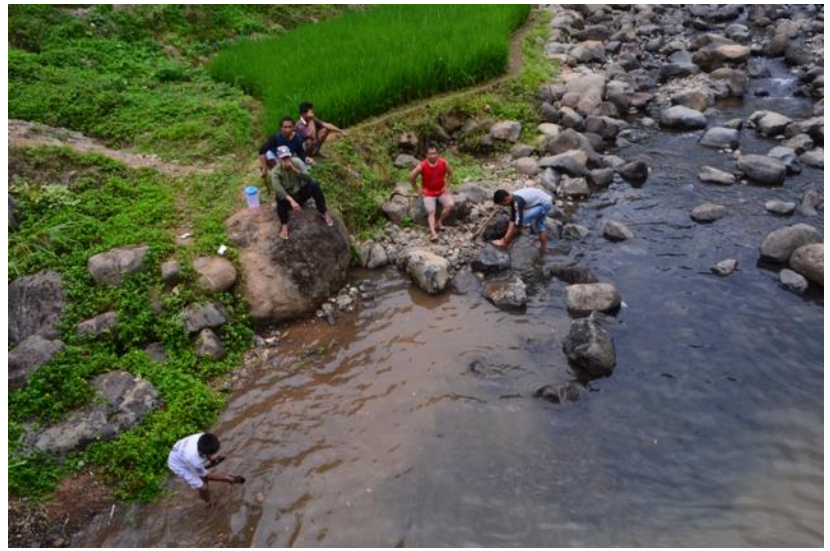

Gambar 4. Warga membuat batasan area sungai untuk menyemaian bibit ikan

Sudah menjadi satu tradisi warga desa Papasan mengadakan acara syukuran atas semua kegiatan inovatif yang telah terlaksana. Hal ini sebagai tanda rasa terima kasih atas semua kekayaan alam yang dimiliki desa. Ada beberapa ritual yang dilakukan yaitu: sambutan dari Kepala Desa, sambutan dari perwakilan tim pengabdian, pembacaan tahlil dan doa oleh sesepuh desa, dan dilanjutkan dengan makan bersama dengan menu utama ingkung ayam yang telah dimasak khusus oleh warga setempat. 


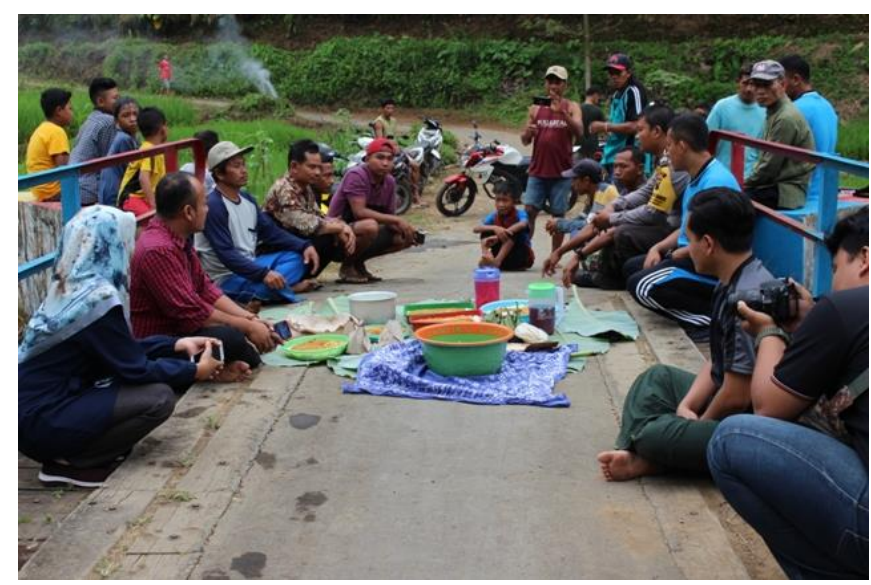

Gambar 5. Acara ritual syukuran warga desa

\section{Tahap Evaluasi Kegiatan}

Evaluasi kegiatan dilaksanakan guna mengetahui keberhasilan kegiatan yang telah dilakukan pada kegiatan pemberdayaan potensi desa wisata ini. Hasil pelaksanaan kegiatan pengabdian kepada masyarakat ini secara garis besar mampu menyadarkan warga desa Papasan akan potensi alam yang bisa menjadi destinasi wisata.

Kepala desa Papasan menyampaikan bahwa dalam kurun waktu satu dua bulan ini banyak warga desa lain yang datang ke desanya untuk sekedar berfoto dan menikmati pemandangan alam desa Papasan yang terdapat icon Pesona Papasan River Walk. Serta momen pulang kampung yang menjadi tradisi warga pada bulan Ramadhan menjelang Idul Fitri menjadi salah satu sebab ramainya pengunjung di area sungai pada sore hari. Tidak jarang para perantau yang kembali ke desa ikut menikmati dan melepas rindu di kampung halamannya. Di sini para perantau juga merasakan inovasi dan pengembangan desa yang semakin baik.

\section{KESIMPULAN}

Pelaksanaan kegiatan pemberdayaan masyarakat ini menghasilkan kesadaran masyarakat untuk ikut andil dalam membangun desa dengan hal-hal inovatif yang dimiliki potensi desa. Adanya icon desa Pesona Papasan River Walk dapat dijadikan sebagai destinasi awal untuk terus mengembangkan desa wisata. Hal ini juga sangat mendukung eksploitasi desa untuk turut serta mempromosikan potensi desa yang pada akhirnya dapat meningkatkan taraf hidup warganya. Sehingga akan meminimalisir warga yang akan merantau ke kota-kota besar untuk mendapatkan pekerjaan. 


\section{SARAN}

Program kemitraan ini diharapkan dapat ditindaklanjuti untuk terus menggali potensi-potensi desa dari segi budaya dan pengolahan hasil bumi. Sehingga tidak hanya dari sisi lingkungan dan keindahan alam saja menjadi fokus kegiatan pemberdayaan masyarakat. Adanya penyuluhan materi kewirausahaan untuk masyarakat agar menambah wawasan untuk berwirausaha.

\section{DAFTAR PUSTAKA}

Adyla S., Nur dan Nurlaela. 2018. Strategi Pengembangan Desa Wisata Berbasis Kearifan Lokal Di Desa Tammangalle Polewali Mandar. Jurnal Plano Madani. Vol.7 No.2 Oktober 2018, 132-141.

Hadiwijoyo, Suryo Sakti. 2012. Perencanaan Pariwisata Perdesaan Berbasis Masyarakat. Yogyakarta: Graha Ilmu.

Pitana, I Gede dan Diarta, I Ketut Surya. 2009. Pengantar Ilmu Pariwisata. Yogyakarta: Andi Publishing.

Yoeti A. Oka. 2008. Perencanaan dan Pengembangan Pariwisata. Jakarta: Pradnyaparamita.

Zakaria, Fariz. dan Suprihardjo, Rima. 2014. Konsep Pengembangan Kawasan Desa Wisata di Desa Bandungan Kecamatan Pakong Kabupaten Pamekasan. Jurnal Teknik POMITS Vol. 3. No. 2 Surabaya. 